The admission also offered an appreciation that the team already had transferable skills, confidence and experience to carry out this care. The reflection of the last team within the hospice to care for a young adult highlighted:

'A mountain has been climbed; the final piece of the jigsaw is in place'.

Conclusions Evaluation challenges the misconception that adult hospices have nothing to offer young adults with palliative care needs. It also affirms that the skills the team already have are transferable.

\section{P-114 YOU SAID, WE DID: HEARING THE YOUNG ADULT VOICE}

Sheonad Laidlaw, Fiona Wylie. The Prince and Princess of Wales Hospice, Glasgow, UK

\subsection{6/spcare-2021-Hospice.131}

Background Those living with life-limiting conditions and physical disability are living longer (McLaughlin, Marosi, Robb, 2020; Landfelt, Thompson, Sejersen, et al., 2020). Advancing age can bring increasing disability and dependence, contrasted with a desire for autonomy and control. At home, such young adults create useable and safe environments around them, achieving more independent living (Bann, Abresch, Biesecker, et al., 2015; Frank, 2020). The lack of such an environment within a hospice may be a barrier to using the services on offer.

Aims

- To understand what is important to a young adult on admission to a hospice inpatient unit (IPU).

- To create an independent and accessible environment for young adults at The Prince and Princess of Wales Hospice.

Methods SHANARRI wellbeing indicators (Scottish Government. Getting it right for every child (GIRFEC), 2017) - safe, healthy, achieving, nurtured, active, responsible, respected and included - were used as a template to gather feedback following a young adult's IPU stay. This involved a one-to-one conversation, capturing verbatim what they said. A process of change was then commenced, and the results shared with the young adult: 'You said, we did'.

Results The young adult identified that access to the following items in the IPU were essential to ensure wellbeing during their stay:

- Equipment: e.g., profiling bed, mattress, tracking hoist.

- Technology: e.g., gaming, computer, phones, WiFi.

- Environmental controls: e.g., lighting, heating, call system, monitoring.

Conclusions Feedback in the form of 'You said, we did' demonstrates commitment to listening and responding, enables rich communication, generates feelings for the young adult of being respected and appreciated, and accelerates adoption of a wide range of changes by the hospice for the young adults. Using verbatim what the young adult said made the case for change personal and more credible. Connection to, and control of, their world, through technology and environmental controls, contributes to their overall mental health and wellbeing. Reproducing their home environments ensures that, when in new surroundings, they are not wholly dependent on others but rather they are safe, achieving, and more independent.

\section{P-115 BUILDING CARERS' RESILIENCE AND WELL-BEING INTEGRATED WITHIN A RESPITE PROGRAMME}

Helen Reeves, Katie Burbridge, Debra Varnam. St Giles Hospice, Whittington, UK

10.1136/spcare-2021-Hospice. 132

Improving end-of-life care is a strategic priority for commissioners and has been for some years. The mean number of hospital admissions in the last 12 months of life averaged in England is 2.28 occupying 30.05 bed days (Bardsley, Georghiou, Spence, et al., 2019). A Carers UK (2016) survey identified that carer breakdown led to unnecessary, distressing and expensive admissions to hospital of the person being cared for, and suggested that if the carer had greater and higher quality support, it could have a significant impact on the number of emergency admissions.

St Giles Hospice recognised that there was still more needed to enable families and patients to feel supported at home. After speaking to families, patients and community healthcare professionals, the organisation identified a gap in service provision for respite care. Consequently, in March 2021 St Giles launched a new respite service which was funded by the generosity of a local business. The aim of that service was to provide support to patients and carers in the last 12 months of life by providing respite care and education within the home setting. This will be achieved through:

- Building resilience and wellbeing within the carer.

- Increasing knowledge and skills for informal carers to support them in the provision of care to those they are caring for.

- Offering respite care in the home causing minimal disturbance to the patient and provide the carer with a muchneeded break.

- Supporting patients and carers to maximise the scope for selfcare and to combine formal and informal support.

- Acting as a flexible, responsive service.

- Supporting the wider shift from hospital to primary care by avoiding hospital admissions.

- Ensuring staff are trained as 'train the trainers' with additional skills in dementia care as it is acknowledged that dementia is not only a primary but a secondary diagnosis and the number of people of dementia is increasing as people live longer.

\section{P-116 SUPPORTING CARERS DURING A PANDEMIC - TRANSFORMING DEMENTIA CARERS' SUPPORT}

${ }^{1}$ Helen Reeves, ${ }^{1}$ Gina Gardner, ${ }^{2}$ Fiona McCracken, ${ }^{2}$ Asima Hussain, ${ }^{2}$ Pat Roberts. ${ }^{1}$ St Giles Hospice, Whittington, UK; ${ }^{2}$ GreenSquare Accord, Walsall, UK

\subsection{6/spcare-2021-Hospice. 133}

Dementia is a far-reaching disease and it is estimated that approximately 850,000 people are living with dementia in the $\mathrm{UK}$; this is estimated to increase to over 1 million by the year 2025 (Prince, Knapp, Guerchet, et al., 2014).

Caring for people with dementia is demanding and this care is often provided by unpaid carers in the home (National Institute for Health Research, 2016). So often people are uncertain about what the future could hold following diagnosis and how to support a person with dementia. Due to this 
in 2017, St Giles Hospice in collaboration with Green Square Accord launched a four-week carers' course which was designed to support unpaid carers in the community who support people living with dementia. The course covers a range of topics, including looking after yourself and activities for people with dementia, eating and drinking and infections in dementia, dementia related behaviours and planning for the future including end-of-life.

Prior to 2020 this four-week course was face-to-face and was group based. When the COVID-19 pandemic hit the service had to act quickly to ensure the much-needed support for these carers did not disappear. The carers' course was adapted to provide support via a one-to-one basis either via video consultation or through a telephone call. This ensured that carers were not isolated and had access to specialist support and signposting to other services. Data captured showed that $100 \%$ of participants found that the topics covered were relevant to their situations, 92\% of participants found that sessions fulfilled their expectations and that $100 \%$ were given opportunity to ask questions. Over 80 carers have been supported through the adaptation of the service so far.

\section{P-117 LAST DAYS MATTER - A PROGRAMME TO HELP LAY FAMILIES LOOK AFTER THEIR LOVED ONES AT HOME}

Sophy Horner, Maddy Bass, Sue McGraw. St John's Hospice, Lancaster, Lancashire

\subsection{6/spcare-2021-Hospice.134}

Many people would like to die at home, but their loved ones can be nervous about looking after them fearing their own lack of clinical knowledge. Family and local health system engagement told us there was a gap in the provision of nonclinical family education.

'Last Days Matter' is the idea of the North Lancashire Compassionate Communities Group, who after research decided to develop their own programme that would support people without clinical expertise to look after their loved ones at home. The Group used their lay and clinical experiences to develop a three-hour programme consisting of five sessions. Each session is made up of a short film that follows the experience of John who is dying, and discussion time. Each session addresses a need that engagement had revealed; planning for the future; to care and accompany; saying goodbye, recognising the signs of dying and the new normal.

We learnt that it was necessary to seek funding for professional actors and filming skills so that we could have a programme that would be professional and how important it was to seek the expertise of the patient and public for their feedback on all scripts and teaching materials.

The result is a programme that is now ready to be used in local communities and has attracted the interest of North West NHS England and NHS Improvement. The programme will be made available further afield for adoption or adaption. It will support people to care for their loved ones at home by giving them the knowledge, reassurance and some of the necessary skills. Initial feedback from engagement and contributors suggests that 'Last Days Matter' is much needed, will be sought after and will be valued by those who need it most. It will also support palliative care staff across the health community.

\section{P-118 IMPROVING CARER SUPPORT IN HOSPICE CARE}

Amanda Wilkins, Barbara Ruff, Zoe Holman. St. Margaret's Hospice Care, Taunton and Yeovil, UK

\subsection{6/spcare-2021-Hospice. 135}

Background Carers provide vital support to patients yet manage a variety of emotional and physical demands themselves (Ates, Ebenau, Busa, et al., 2018). Use of 'carer needs' tools have been shown to reduce carer strain (Aoun, Grande, Howting, et al., 2015). Tools need to be part of wider organisational behavioural and cultural shift to improve person-centred support for carers (Diffin, Ewing, Harvey, et al., 2018). A quality improvement approach encompasses the wider factors involved in changing behaviours and culture in an organisation (NHS England. NHS Change Model).

Aims To evaluate the effectiveness of a quality improvement programme targeting carer support at the hospice.

Methods Baseline audit of 18 records carried out (2019) against the following standards; carers identified, relationship of carer documented, main carer identified, carer limitations documented, identification of needs, separate carer record and carer needs addressed.

Measures implemented share the vision, carer champions identified, record templates modified, staff awareness and process training, promotion of carer resources, embed change. Reaudit of 15 records (2021) to identify impact of improvements.

Results In only 72\% of cases a carer was identified in 2019 compared to $100 \%$ at review. Compliance with five of the standards in 2019 was between $17 \%$ and $22 \%$ of the records audited. Average compliance across seven standards in 2019 was 39\% and in 2021 compliance was 71\%. The re-audit identified a marked improvement in six of the standards audited. In over $90 \%$ of cases, the relationship of carer to patient was recorded successfully in both audits.

Conclusion Compliance with the standards increased by $32 \%$ on average. The measures implemented were effective at increasing the evidence and awareness of carer support in the organisation. Further improvements are needed in: where information is recorded, assessment of carer limitations and recording of intervention outcomes. Further quality improvements planned include sharing the outcome of the re-audit to provide ongoing momentum, increase number of carer champions and carer support to be incorporated at strategic level.

\section{P-119 SOLIDARITY, SKILLS AND SUPPORT- ST CATHERINE'S (LANCASHIRE) 'WINTER PRESSURES' CARE HOMES PROJECT}

${ }^{1,2}$ Claire Capewell, ${ }^{2}$ Deborah Bolton, ${ }^{2}$ Katherine Wilkinson, ${ }^{2}$ Victoria Hargreaves. ${ }^{1}$ Lancashire Teaching Hospitals NHS Trust, Preston, UK; ${ }^{2}$ St Catherine's Hospice, Preston, UK

10.1136/spcare-2021-Hospice. 136

Background Care homes have been particularly badly affected by the events of 2020 . We acquired short-term resource from two streams to improve system resilience during winter.

Aims To assess the impact of enhanced specialist palliative care to care homes regarding responsiveness, professional support and education, referrals, advance care planning (ACP), hospital admissions and deaths in preferred place of death (PPD).

Methods A free education programme was offered to all care homes in Preston, Chorley and South Ribble commencing in 